combination therapy; 3 . Initial combination therapy with prednisone; or 4. Initial combination therapy with infliximab. During the 10-year follow-up period treatment was steered at low disease activity (DAS $\leq 2.4$ ) and adjusted every three months when necessary. After 10-years patients were treated and followed-up according to regular care. We explored mortality through the Dutch state registry for mortality (Centrum voor Familiegeschiedenis) and treating rheumatologist. Mortality in the BeSt cohort was compared to the general Dutch population (Statistics Netherlands) matched by gender, age and calendar year using the standardized mortality ratio (SMR). Kaplan-Meier curves and the log-rank test were used to compare survival among the initial treatment strategies.

Results: The mean duration of follow-up in non-deceased patients was 17 years (range 16-18). In total, 143 patients died (28\%) compared to a total of $105(21 \%)$ expected deaths in the reference population. The overall SMR after 17 years was 1.37 (95\% Cl: $1.16-1.61)$. Within the study population, no statistically significant difference in survival-curves was observed between the four initial treatment strategies (log-rank $\mathrm{p}=0.76$ ) (table 1, and figure 1).

Table 1. BeSt study cohort mortality - stratified for initial treatment strategy

\begin{tabular}{|c|c|c|c|c|}
\hline & $\begin{array}{c}\text { Sequential } \\
\text { monotherapy } \\
n=126\end{array}$ & $\begin{array}{c}\text { Step-up } \\
\text { combination } \\
\text { therapy } n=121\end{array}$ & $\begin{array}{l}\text { Initial combination } \\
\text { therapy with } \\
\text { prednisone } n=133\end{array}$ & $\begin{array}{c}\text { Initial combination } \\
\text { therapy with } \\
\text { infliximab } n=128\end{array}$ \\
\hline N (\%) † & $38(30)$ & $31(26)$ & $41(31)$ & $33(26)$ \\
\hline SMR $(95 \% \mathrm{Cl})$ & $1.41(1.03-1.94)$ & $1.20(0.84-1.70)$ & $1.53(1.13-2.09)$ & $1.31(0.93-1.85)$ \\
\hline
\end{tabular}

SMR: standardized mortality ratio (number observed deaths/number expected deaths); $\mathrm{Cl}$ : confidence interval.Conclusion:

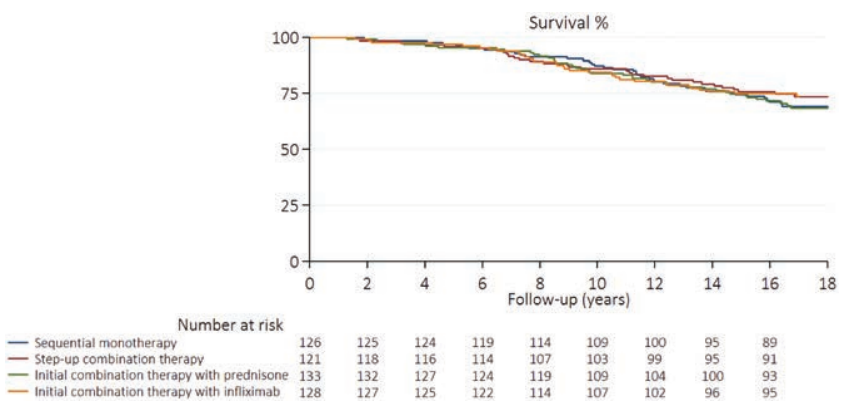

Figure 1. Survival curves - stratified for initial treatment strategy

After a mean of 17 years follow-up the mortality was increased in the BeSt study cohort when compared to the general Dutch population. We observed no difference in survival curves among the four treatment strategies.

Disclosure of Interests: Johanna M. Maassen: None declared, Yvonne Goekoop-Ruiterman: None declared, Hans van Groenendael: None declared, WIllem Lems Grant/research support from: Pfizer, Consultant of: Lilly, Pfizer, Pit Kerstens: None declared, Thomas Huizinga Grant/research support from: Ablynx, Bristol-Myers Squibb, Roche, Sanofi, Consultant of: Ablynx, Bristol-Myers Squibb, Roche, Sanofi, Cornelia Allaart: None declared

DOI: 10.1136/annrheumdis-2020-eular.869

\section{OP0220 ASSESSING THE EFFECT OF INCREASED BODY MASS INDEX ON RESPONSE TO TNF INHIBITORS IN ESTABLISHED RHEUMATOID ARTHRITIS: RESULTS FROM THE METEOR DATABASE}

M. Dey ${ }^{1,2}$, S. S. Zhao ${ }^{1,2}$, R. J. Moots ${ }^{1,2}$, R. B. M. Landewés ${ }^{3,4}$, N. Goodson ${ }^{1,2}$ ${ }^{1}$ Institute of Ageing and Chronic Disease, University of Liverpool, Musculoskeletal Biology I, Liverpool, United Kingdom; ${ }^{2}$ Aintree University Hospital, Liverpool University Hospitals NHS Foundation Trust, Academic Rheumatology, Liverpool, United Kingdom; ${ }^{3}$ Amsterdam Rheumatology \& Immunology Center, Amsterdam, Netherlands; ${ }^{4}$ Atrium MC, Rheumatology, Heerlen, Netherlands

Background: Rheumatoid arthritis (RA) is associated with increased body mass index (BMI)- $60 \%$ of patients are either overweight or obese. Obesity in RA has been shown to predict reduced response to biologic therapy including tumour-necrosis-factor inhibitors (TNFi) [1]. However, it is not clear whether increased BMI influences response to all TNFi drugs in RA.

Objectives: 1.To explore whether BMI is associated with response to TNFi in patients with established rheumatoid arthritis (estRA), including those newly-starting on these drugs.
Methods: Participants with estRA (>1year since diagnosis) taking biologic medications, registered on METEOR (international database of RA patients) 2008-2013, were included. EULAR response, DAS28 remission (including components), and treatment regimens were recorded at baseline, 6 , and 12 months WHO definitions of overweight $(B M I \geq 25)$ and obese $(B M I \geq 30)$ were explored as predictors of TNFi response (good EULAR response and DAS28 remission) using normal BMI as comparator. Logistic and linear regression models (controlling for age, gender, smoking, and baseline outcomes) and sensitivity analyses were performed. Subgroup analyses were performed for grouped TNFi and individual TNFi (infliximab, IFX; adalimumab, ADA; etanercept, ETN).

Results: 247 patients with estRA were taking a biologic at 6 months, and 231 patients were taking a biologic at 12 months. Obese patients taking any biologic were significantly less likely to achieve DAS28 remission (OR $0.33[95 \% \mathrm{Cl} 0.12$ $0.80]$ ) or good EULAR response (OR 0.37 [95\% Cl 0.16-0.81]) after 6 months, compared to those of normal BMl; this was also demonstrated in those co-prescribed methotrexate (DAS28 remission: OR 0.23 [95\% $\mathrm{Cl} 0.07-0.62]$; good EULAR response: OR $0.39[95 \% \mathrm{Cl} 0.15-0.92])$. These associations did not remain statistically significant at the 12 months assessment.

Regarding specific anti-TNF therapies, RA patients treated with monoclonal antibody (-mab) TNFis (IFX/ADA/ GOL) were significantly less likely to achieve good EULAR response at 6 months if they were obese RA $(n=38)$, compared to those of normal weight $(n=44)$ (OR 0.17 [95\%Cl 0.03-0.59]). A similar non-significant difference was demonstrated for DAS28 remission, and 12-month remission. Specifically, obese individuals were significantly less likely to achieve good EULAR response at 6 months with IFX (OR 0.09 [95\% Cl 0.00-0.61]; $n=20$ ), and significantly less likely to achieve DAS28 remission at 6 months when newly-starting ADA (OR 0.14 [95\% $\mathrm{Cl} 0.01-0.96] ; n=17$ ), compared to those of normal weight. There were no significant differences in remission outcomes between individuals of different BMI taking ETN. A small number of individuals stopped taking their respective biologic after 6 months; reason for cessation was not recorded. Similar outcomes were seen in patients already established on anti-TNF therapy, with overweight and obese individuals less likely overall to be in DAS28 remission at all time points.

Conclusion: In established RA, obesity is associated with reduced treatment response to -mab TNFi. No association between increased $\mathrm{BMI}$ and response to ETA was observed. Using BMI to direct biologic drug choice could prove to be a simple and cost-effective personalised-medicine approach to prescribing.

References:

[1] Schäfer M, MeißnerY, Kekow J, Berger S, Remstedt S, Manger B, et al. Obesity reduces the real-world effectiveness of cytokine-targeted but not cell-targeted disease-modifying agents in rheumatoid arthritis. Rheumatology. 2019 Nov 20.

Disclosure of Interests: Mrinalini Dey: None declared, Sizheng Steven Zhao: None declared, Robert J Moots: None declared, Robert B.M. Landewé Consultant of: AbbVie; AstraZeneca; Bristol-Myers Squibb; Eli Lilly \& Co.; Galapagos NV; Novartis; Pfizer; UCB Pharma, Nicola Goodson: None declared DOI: 10.1136/annrheumdis-2020-eular.1084

\section{OP0221 \\ HAVE 5-YEAR SURVIVAL RATE AND MORTALITY CHANGED IN PATIENTS WITH EARLY RHEUMATOID ARTHRITIS IN THE PAST TWENTY YEARS?-RESULTS FROM THE IORRA COHORT}

N. Sugitani ${ }^{1}$, E. Tanaka ${ }^{1}$, E. Inoue ${ }^{1,2}$, M. Abe ${ }^{1}$, E. Sugano $^{1}$, K. Saka ${ }^{1}$, M. Ochiai ${ }^{1}$, Y. Shimizu ${ }^{1}$, R. Yamaguchi ${ }^{1}$, N. Sugimoto ${ }^{1}$, K. Ikari ${ }^{3}$, A. Nakajima ${ }^{1,4}$, A. Taniguchi ${ }^{1}$, H. Yamanaka ${ }^{1,5}$, M. Harigai ${ }^{1} .{ }^{1}$ Department of Rheumatology, Tokyo Women's Medical University School of Medicine, Tokyo, Japan; ${ }^{2}$ Division of Medical Informatics, St. Marianna University School of Medicine, Kanagawa, Japan; ${ }^{3}$ Department of Orthopedic Surgery, Tokyo Women's Medical University, Tokyo, Japan; ${ }^{4}$ Center for Rheumatic Diseases, Mie University Hospital, Mie, Japan; ${ }^{5}$ Rheumatology, Sanno Medical Center, Tokyo, Japan

Background: The mortality of patients with rheumatoid arthritis (RA) had been reported as being worse than that of the general population [1, 2], but is expected to have improved over time because the progress in treatment of RA during the past twenty years has been actively adopted to RA management [3 4]. However, the change in the mortality still remains controversial in patients with early RA $[5,6]$

Objectives: To investigate whether the vital prognosis of patients with early RA has changed in the past twenty years.

Methods: The IORRA cohort is a large observational cohort established in 2000 at the Institute of Rheumatology, Tokyo Women's Medical University. Essentially, all Japanese patients diagnosed with RA at our institute were registered and clinical parameters were assessed biannually. As there is no National Death Registry in Japan, we obtained death report from residual families who responded to our mail query to patients who failed to conduct the subsequent IORRA survey, from physicians of affiliated hospitals and from police in case they found dead 
patient outside of a hospital. In this study, the patients with early RA (less than 2 years of disease duration) who participated in the survey for the first time from 2001 to 2012 were included and observed for five years from the date of the initial survey. We classified patients into group A (enrolled in 2001-2006) and B (enrolled in 2007-2012). Five-year survival rate and standardized mortality ratio (SMR) were calculated for each group. SMR was calculated using the life tables in Japanese general population reported by the Ministry of Health, Labour and Welfare, Japan. The effects of loss to follow-up cases were evaluated by multiple imputation method as a sensitivity analysis of SMR.

Results: A total of 3,217 patients with early RA were analyzed. The number of patients was 1,609 (79.4\% female) in the group $A$ and 1,608 ( $81.8 \%$ female) in $\mathrm{B}$. The median age at baseline was 55 in both groups. Among a total of 3,217 patients, $486(15.1 \%)$ patients were lost during 5-year follow-up; 213 $(13.2 \%)$ in the group $A$ and $273(17.0 \%)$ in B, respectively. During the observational period, deaths were confirmed in 47 cases (2.9\%) in the group $A$ and $45(2.8 \%)$ in $B$. Major causes of death included malignancies $(28 \%$ in the group $A, 38 \%$ in $B$ ), respiratory involvement (23\% in the group A, $40 \%$ in B), cerebrovascular disorders ( $11 \%$ in the group $A, 2 \%$ in $B)$, and cardiovascular disorders ( $11 \%$ in the group A, $0 \%$ in $B)$. The five-year survival rate was $88.8 \%$ for the group $A$ and $87.8 \%$ for $B$, and the SMR was $0.81(95 \% \mathrm{Cl}: 0.59-1.08)$ for the group $A$ and 0.78 (0.57-1.04) for $B$ when assuming all the lost to follow-up patients were alive for 5 years. In the sensitivity analysis assuming that the mortality rate of patients who were lost to follow-up was twice as that of the general population, the SMR was $0.90(0.68-1.19)$ for the group A and 0.92 (0.68-1.23) for $\mathrm{B}$

Conclusion: The mortality of patients with early RA in the past twenty years has been comparable to that of the Japanese general population. In addition, the SMR and the five-year survival rate did not change overtime.

References:

[1] Cobb, S., et al. N Engl J Med 1953; 249(14): 553-556.

[2] Nakajima, A., et al. Scand J Rheumatol 2010; 39(5): 360-367.

[3] Smolen, J. S., et al. Ann Rheum Dis 2014; 73(3): 492-509.

[4] Singh, J. A., et al. Arthritis Care Res 2016; 68(1): 1-25.

[5] Lacaille, D., et al. Ann Rheum Dis 2017; 76(6): 1057-1063.

[6] Humphreys, J. H., et al. Arthritis Care Res 2014; 66(9): 1296-1301.

Disclosure of Interests: Naohiro Sugitani: None declared, Eiichi Tanaka Consultant of: Abbvie, Asahi Kasei pharma co., Bristol Myers Squibb, Chugai Pharmaceutical, Daiichi Sankyo Co., Eisai Pharmaceutical, Janssen Pharmaceutical K.K., Nippon Kayaku, Pfizer, Takeda Pharmaceutical, Taisho Toyama Pharmaceutical Co., and UCB Pharma., Eisuke Inoue Speakers bureau: EI has received speaker fee from Bristol-Meyers, Pfizer, Merck serono., Mai Abe: None declared, Eri Sugano: None declared, Kumiko Saka: None declared, Moeko Ochiai: None declared, Yoko Shimizu: None declared, Rei Yamaguchi: None declared, Naoki Sugimoto: None declared, Katsunori Ikari Speakers bureau: Asahi Kasei Pharma Corp., Astellas Pharma Inc., AbbVie Japan GK, Ayumi Pharmaceutical Co., Bristol Myers Squibb Co., Ltd., Chugai Pharmaceutical Co., Ltd., Eis, ai Co., Ltd., Eli Lilly Japan K.K., Janssen Pharmaceutical K.K., Kaken Pharmaceutical Co. Ltd., Mitsubishi Tanabe Pharma Corp.Pfizer Japan Inc., Takeda Pharmaceutical Co. Ltd., Teijin Pharma Ltd and UCB Japan Co. Ltd., Ayako Nakajima Grant/ research support from: AN has received research grants from Chugai Pharmaceutical Co., Ltd., Mitsubishi Tanabe Pharma Co., Pfizer Japan Inc., Consultant of: AN has consultant fee from Nippon Kayaku Co. Ltd., Speakers bureau: AN has received speaker's fee from AbbVie Japan GK, Actelion Pharmaceuticals Japan LTD., Asahi Kasei Pharma Co., Astellas Pharma Inc., Ayumi Pharmaceutical Co., Bristol Myers Squibb Co., Ltd., Chugai Pharmaceutical Co., Ltd., Eisai Co., Ltd., Eli Lilly Japan K.K., GlaxoSmithKline K.K., Hisamitsu Pharmaceutical Co. Inc., Kyorin Pharmaceutical Co. Ltd., Mitsubishi Tanabe Pharma Co., Otsuka Pharmaceutical Co. Ltd., Pfizer Japan Inc., and Teijin Pharma Ltd., Atsuo Taniguchi: None declared, Hisashi Yamanaka Grant/research support from: HY has received research grant or speaker fee from AbbVie, Astellas, Ayumi, Behringer, Bristol-Meyers, Chugai, Daiichi-Sankyo, Eisai, Kaken, Nippon-Shinyaku, Novartis, Ono, Pfizer, Taisyo-Toyama, Takeda, Tanabe-Mitsubishi, Teijin Pharma, Torii, UCB, YLbio., Speakers bureau: HY has received research grant or speaker fee from AbbVie, Astellas, Ayumi, Behringer, Bristol-Meyers, Chugai, Daiichi-Sankyo, Eisai, Kaken, Nippon-Shinyaku, Novartis, Ono, Pfizer, Taisyo-Toyama, Takeda, Tanabe-Mitsubishi, Teijin Pharma, Torii, UCB, YLbio., masayoshi harigai Grant/ research support from: AbbVie Japan GK, Ayumi Pharmaceutical Co., Bristol Myers Squibb Co., Ltd., Eisai Co., Ltd., Mitsubishi Tanabe Pharma Co., Nippon Kayaku Co., Ltd., and Teijin Pharma Ltd. MH has received speaker's fee from AbbVie Japan GK, Ayumi Pharmaceutical Co., Boehringer Ingelheim Japan, Inc., Bristol Myers Squibb Co., Ltd., Chugai Pharmaceutical Co., Ltd., Eisai Co., Ltd., Eli Lilly Japan K.K., GlaxoSmithKline K.K., Kissei Pharmaceutical Co., Ltd., Oxford Immuotec, Pfizer Japan Inc., and Teijin Pharma Ltd. MH is a consultant for AbbVie, Boehringer-ingelheim, Kissei Pharmaceutical Co., Ltd. and Teijin Pharma. DOI: 10.1136/annrheumdis-2020-eular.1134

\section{\begin{tabular}{|l|l|l|l|}
\hline OP0222 & IS REFERRING EARLY ARTHRITIS PATIENTS WITHIN
\end{tabular} 6 WEEKS ASSOCIATED WITH BETTER LONG-TERM OUTCOMES THAN REFERRING WITHIN 12 WEEKS AFTER SYMPTOM ONSET? - INVESTIGATING THE EVIDENCE FOR THE FIRST EULAR RECOMMENDATION FOR EARLY ARTHRITIS IN TWO OBSERVATIONAL COHORTS}

E. Niemantsverdriet ${ }^{1}$, M. Dougados ${ }^{2}$, B. Combe ${ }^{3}$, A. Van der Helm - van Mil ${ }^{1}$. ${ }^{1}$ Leiden University Medical Center (LUMC), Leiden, Netherlands; ${ }^{2}$ Hospital Cochin, Paris, France; ${ }^{3}$ Chu Montpellier St Eloi, Montpellier, France

Background: EULAR- recommendations for management of early arthritis formulated that patients should be referred to, and seen by a rheumatologist, within 6 -weeks after symptom onset. The mentioned period of $\leq 6$-weeks after symptom onset is shorter than $\leq 12$-weeks, the period that is generally considered as the 'window-of-opportunity'. Because implementation provides challenges, and evidence supporting that referral $\leq 6$-weeks is better than e.g. $<12$-weeks is missing, we investigated if $\leq 6$-weeks relates to improved long-term outcomes.

Objectives: We used an observational study design to investigate in two cohorts if time-to-encounter (TtE) a rheumatologist $\leq 6$-weeks, compared to 7-12-weeks, results in better disease long-term outcomes, measured with sustained DMARDfree remission (SDFR) and radiographic progression.

Methods: Consecutive 1987-RA patients of the Leiden EAC $(n=1025)$ and ESPOIR ( $n=514$ ) were studied during median 7 and 10 years follow-up. Patients were categorized on duration between symptom onset and first encounter with a rheumatologist; $\leq 6-$, 7-12-, and >12-weeks. Multivariable Cox regression (SDFR), linear mixed models (radiographic progression), and meta-analyses were used. Results: Leiden RA-patients encountered the rheumatologist within 6-weeks obtained SDFR more often than patients seen within 7-12-weeks (HR 1.59, 95\% $\mathrm{Cl}: 1.02-2.49$ ), and >12-weeks (HR 1.54, 95\% Cl:1.04-2.29). In ESPOIR, similar but non-significant effects were observed; meta-analysis showed that within 6-weeks was better than 7-12-weeks (HR 1.69, 95\%Cl:1·10-2.57, Figure 1 A) and >12-weeks (HR 1.67, 95\% Cl:1.08-2.58). Patients encountered the rheumatologist within 6-weeks had similar radiographic progression than those seen 7-12-weeks, in any cohort, or meta-analysis (Figure 1-B).

A

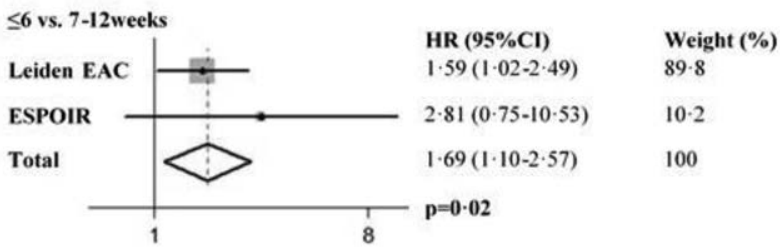

B

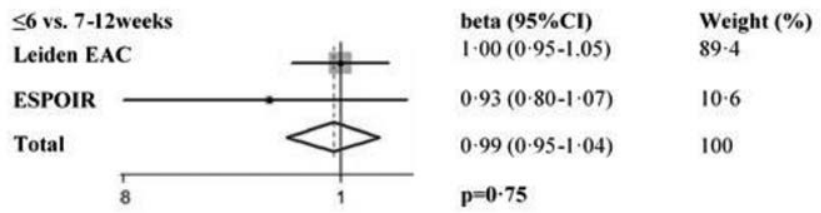

Figure 1 Meta-analyses of time-to-encounter the rheumatologist and the chance of achieving sustained DMARD-free remission $(\mathrm{A})$ and radiographic progression $(\mathrm{B})$

Conclusion: Scientific evidence underlying the first EULAR recommendation depends on the outcome of interest; visiting a rheumatologist within 6-weeks of symptom-onset had clear benefits for achieving SDFR, but not for radiographic progression.

\section{References: None.}

Disclosure of Interests: Ellis Niemantsverdriet: None declared, Maxime Dougados Grant/research support from: AbbVie, Eli Lilly, Merck, Novartis, Pfizer and UCB Pharma, Consultant of: AbbVie, Eli Lilly, Merck, Novartis, Pfizer and UCB Pharma, Speakers bureau: AbbVie, Eli Lilly, Merck, Novartis, Pfizer and UCB Pharma, Bernard Combe Grant/research support from: Novartis, Pfizer, RocheChugai, Consultant of: AbbVie; Gilead Sciences, Inc.; Janssen; Eli Lilly and Company; Pfizer; Roche-Chugai; Sanofi, Speakers bureau: Bristol-Myers Squibb; Gilead Sciences, Inc.; Eli Lilly and Company; Merck Sharp \& Dohme; Pfizer; Roche-Chugai; UCB, Annette van der Helm - van Mil: None declared DOI: 10.1136/annrheumdis-2020-eular.1179 